\title{
Immunogenicity testing of therapeutic antibodies in ocular fluids after intravitreal injection
}

\author{
Uwe Wessels*,1, Markus Zadak1 ${ }^{1}$, Astrid Reiser ${ }^{1}$, Janis Brockhaus², Mirko Ritter ${ }^{2}$, Afsaneh \\ Abdolzade-Bavil ${ }^{1}$, Julia Heinrich ${ }^{1}$ \& Kay Stubenrauch ${ }^{1}$ \\ ${ }^{1}$ Pharmaceutical Sciences, Pharma Research \& Early Development, Roche Innovation Center Munich, Nonnenwald 2, 82377 \\ Penzberg, Germany \\ ${ }^{2}$ Roche Diagnostics GmbH, Roche Innovation Center Munich, Nonnenwald 2, 82377 Penzberg, Germany \\ *Author for correspondence: Tel.: +49 885660 3814; Fax: +49 885660 3268; uwe.wessels@roche.com
}

\begin{abstract}
Aim: High drug concentrations in ocular fluids after intravitreal administration preclude the use of drugsensitive immunoassays. A drug-tolerant immunoassay is therefore desirable for immunogenicity testing in ophthalmology. Experimental: Immune complex (IC) antidrug antibody (ADA) assays were established for two species. The assays were compared with the bridging assay in ocular and plasma samples from two preclinical studies. Results: The IC assays showed high drug tolerance, which enabled a reliable ADA detection in ocular fluids after intravitreal administration. The IC assays were superior to the bridging assay in the analysis of ocular fluids with high drug concentrations. Conclusion: The IC assay allows a reliable ADA detection in matrices with high drug concentrations, such as ocular fluids.
\end{abstract}

First draft submitted: 19 February 2018; Accepted for publication: 22 March 2018; Published online: 11 April 2018

Keywords: antidrug antibody $\bullet$ aqueous humor $\bullet$ drug tolerance $\bullet$ ELISA $\bullet$ immune complex assay $\bullet$ immunogenicity - ophthalmology • safety assessment $\bullet$ vitreous humor

Therapeutic antibodies are increasingly used in ophthalmology to treat inflammatory or angiogenic diseases [1]. Wet age-related macular degeneration is a notable example, where new therapeutics such as bevacizumab, ranibizumab and aflibercept have enabled sight-saving therapy [2]. However, the drugs require chronic intravitreal (IVT) administration with 1-2-month intervals. This high burden on patients has prompted the development of new drug candidates that would require less frequent administration thanks to slower elimination rates, increased binding affinity and higher dosing concentrations [3].

The formation of antidrug antibodies (ADAs) can affect pharmacologic properties of therapeutic antibodies. Most notably, ADAs have a major impact on pharmacokinetics, often leading to faster drug elimination and increased intersubject variability. Immunogenicity assessment therefore comprises an essential part of the development program for therapeutic antibodies, which supports the correct interpretation of pharmacokinetic, pharmacodynamic and safety data. Yet, finding an appropriate immunogenicity testing strategy may pose one of the biggest bioanalytical challenges.

ADA analysis in ophthalmology studies is usually conducted by the systemic detection of ADAs from serum or plasma samples [4] and immunogenicity has been observed after IVT administration in preclinical studies, especially in rabbit and minipig [5,6]. It is assumed that the systemic ADAs are not generated in the eye but are induced following drug clearance through the systemic circulation, for example, via anterior elimination and uveal blood flow [7], because the eye itself is an immune privileged organ with several mechanisms to inhibit immune response [8]. However, specific immune response in vitreous humor $(\mathrm{VH})$ has been observed [9]. The direct ADA analysis in ocular fluids, such as $\mathrm{VH}$ or aqueous humor $(\mathrm{AH})$, would thus support the pharmacokinetic evaluation of IVT-administered therapeutic antibodies and provide valuable insights into the eye's immune system homeostasis.

So far, ADA detection in ocular fluids has not been described. The conventional analysis with a bridging assay is hampered by high residual drug concentrations, which can persist over the whole treatment period due to high IVT doses and long drug retention time in ocular fluids (e.g., half-life for bevazizumab is 9 days) [10]. Residual 
(A)

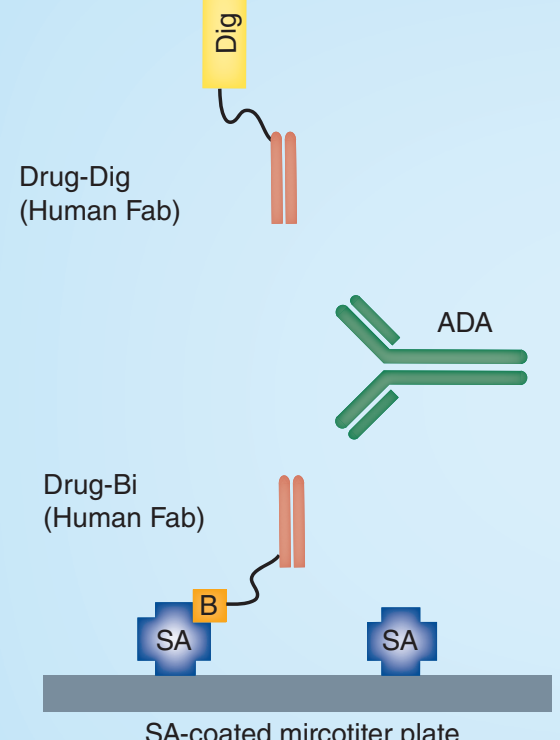

(B)

Anti-Animal

IgG-Dig

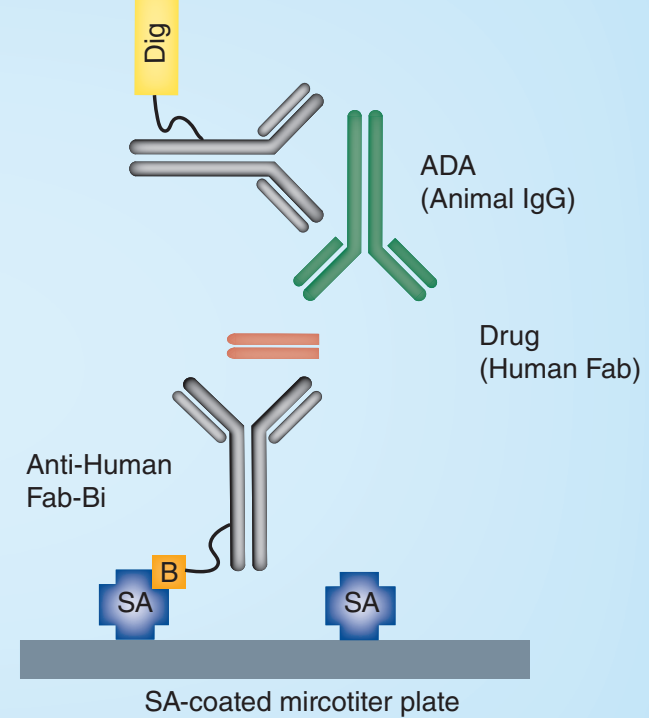

Figure 1. Principles of the bridging and immune complex assays. (A) In the bridging assay, the two antigen-binding sites of an ADA couple the immobilized drug (drug-Bi) with the digoxigenylated drug (drug-Dig) used for detection. (B) In the immune complex assay, a drug-ADA complex is captured by the immobilized anti-human IgG (anti-Human IgG-Bi) and then detected using digoxigenylated anti-animal lgG (anti-animal lgG-Dig).

ADA: Antidrug antibody; Bi: Biotin; Dig: Digoxigenin; SA: Streptavidin.

unlabeled drug interferes with the conventional bridging assay by competing with the labeled drug molecules, thereby increasing the risk of false-negative results (Figure 1A). The problem is further aggravated by the low sample volume available for the analysis, with the typical AH sample volume per eye being $100 \mu \mathrm{l}$ for human [11] and $50 \mu \mathrm{l} \mathrm{AH}$ for cynomolgus monkeys or minipigs. VH samples typically have larger volume; however, human VH samples can only be obtained in rare cases during surgery [12], whereas only terminal VH samples are available in animals. In addition, the $\mathrm{VH}$ requires pretreatment due to its high viscosity [13], which diminishes the occurrence of $\mathrm{VH}$ analysis in bioanalysis. Considering that the conventional ADA analysis consists of two steps (screening and confirmatory bridging assays), the available amount of ocular fluid would usually be insufficient for reliable immunogenicity testing.

Although several approaches can improve drug tolerance of the bridging assay format, for example, acid pretreatment [14,15], affinity capture elution assays [16] or non-ELISA technical platforms such as Meso Scale Discovery (MSD), Gyros [15], Biacore [17] or Octet [18], these approaches have not been demonstrated to be adequate for residual drug concentrations as high as $1000 \mu \mathrm{g} / \mathrm{ml}$, which occur in VH after IVT administration. In addition, the pretreatments would further diminish the already low fluid sample volume. A reliable ADA analysis in ocular fluid thus requires a novel approach with high drug tolerance and low sample consumption.

We have reported several assay formats that addressed the drug tolerance problem in ADA analysis and evaluated them in preclinical studies in cynomolgus monkeys and mice [19-21]. These assay formats rely on the formation of an immune complex (IC) between an ADA and a free drug molecule (Figure 1B). The principle differs fundamentally from that of the bridging assay, requiring the presence of a free unlabeled drug, which makes them intrinsically 
drug tolerant. Moreover, these IC assays do not require an additional confirmatory step because the assay principle precludes the occurrence of false positive signals, for example, by a soluble target [22]. The sensitivity of the bridging and IC assays is comparable; however, the IC assays have lower sample consumption (approximately $5 \mu \mathrm{l}$ ). Overall, these features of the IC assays make them ideal assay formats for ADA analysis in ocular fluid samples.

In this article, we present two IC assays developed for the analysis of ocular fluid samples in cynomolgus monkey and minipig preclinical studies. We evaluate their applicability for ADA analysis in ophthalmological studies and compare them with the conventional bridging assay.

\section{Experimental}

\section{Chemicals, reagents \& equipment}

The murine monoclonal antibodies against cynomolgus monkey $\operatorname{IgG}$ and minipig $\operatorname{IgG}$ were generated from mice immunized with purified cynomolgus monkey or minipig IgG. Antibodies from hybridoma supernatants were purified by protein A chromatography. Conjugates of cynomolgus monkey or minipig IgG with human IgG and anti-human kappa light chain M1.7.10 were generated in house. All antibodies were produced by Roche Diagnostics $\mathrm{GmbH}$, Penzberg, Germany, and were stored in aliquots at $-80^{\circ} \mathrm{C}$ until use. Biotin (Bi)and digoxigenin (Dig)-labeling was performed by Roche Diagnostics GmbH. Polyclonal sheep antibody Fab fragments against Dig coupled with HRP (pAb-Dig-S-Fab-HRP), phosphate-buffered saline (PBS), Tween 20, 2,2'-azino-bis-3-ethylbenzthiazoline-6-sulphonic acid (ABTS; ready to use solution), bovine plasma albumin and Roche Universal buffer were obtained from Roche Diagnostics GmbH. Low Cross Buffer ${ }^{\circledR}$ was from Candor Bioscience GmbH (Wangen, Germany). Individual and pooled minipig sodium citrate, theophylline, adenosine and dipyridamol (CTAD) plasma, as well as individual and pooled cynomolgus monkey CTAD plasma for in vitro studies was obtained from Sera Laboratory International Ltd (Haywords Heath, Sussex, UK). Streptavidin-coated microtiter plates (SA-MTPs) were from Microcoat Biotechnologie GmbH (Bernried, Germany).

\section{Study samples}

Study samples were obtained from preclinical tolerability studies with a human IgG1 Fab fragment as the drug. Minipig samples were obtained from eight animals that received an IVT administration in both eyes at day 1 and and again at day 28 at either of two different dose levels $(5 \mathrm{or} 10 \mathrm{mg} /$ eye dose groups). CTAD plasma samples were taken prior dosing and $4 \mathrm{~h}$ and then 1, 3, 7 and 10 days after first and second dosing. One additional sample was taken terminally, 71 days after first dosing. Approximately $250 \mu \mathrm{l} \mathrm{VH}$ sample was taken terminally (day 35 , 44 or 71 ) from each animal from the right eye. Although AH samples were also taken, they could not be analyzed due to insufficient sample volume.

Cynomolgus samples were obtained from eight animals that received IVT administrations in both eyes at day 1 and again at day 29 at either of two different dose levels ( 5 or $10 \mathrm{mg} /$ eye dose groups). CTAD plasma samples were taken prior dosing and 4, 7, 24, 33, 48, 72 and $120 \mathrm{~h}$ after each dosing. AH of the right eye (approximately $30 \mu \mathrm{l}$ ) were taken on days 8,35 and 43 after first dosing. VH samples (approximately $250 \mu \mathrm{l}$ ) were obtained terminally (day 43) from each animal from the right eye.

All samples were immediately frozen after acquisition and thawed prior to analysis. Cynomolgus and minipig VH samples were thawed and centrifuged prior to analysis at 13,000 $\times g$ for 5 min. Supernatant was taken for analysis.

\section{Bridging ADA assay}

ADAs against the drug (human IgG 1 Fab fragment) were detected in $\mathrm{AH}, \mathrm{VH}$ and plasma samples from minipig and cynomolgus monkey using a one-step ELISA (Figure 1A). Affinity-purified anti-idiotypic monoclonal mouse antibodies directed against the complementarity-determining regions (CDRs) of the drug spiked into blank matrix were used as quality control (QC) samples. The QC concentrations were $750 \mathrm{ng} / \mathrm{ml}$ (high-concentration quality control [HQC]) and $15 \mathrm{ng} / \mathrm{ml}$ (low-concentration quality control [LQC]) for the cynomolgus and minipig assays. Reagents and samples were incubated at room temperature with shaking at $500 \mathrm{rpm}$. Roche Universal buffer was used as assay buffer; PBS containing $0.05 \%$ Tween 20 was used as washing buffer.

Samples were diluted 1:20 with assay buffer containing Bi- and Dig-labeled drug (each at $0.5 \mu \mathrm{g} / \mathrm{ml}$ final assay concentration), incubated for $1 \mathrm{~h}$ and then transferred onto an SA-MTP. The plate was incubated for $1 \mathrm{~h}$ and washed three-times with $300 \mu \mathrm{l}$ washing buffer. Afterwards, $100 \mu \mathrm{l}$ pAb-Dig-S-Fab-HRP $(12.5 \mathrm{mU} / \mathrm{ml})$ was added to each sample and the plate was incubated for $1 \mathrm{~h}$. After washing, $100 \mu \mathrm{l}$ ABTS was added to each well and 
the ensuing color reaction was monitored by photometrical readout at $405 \mathrm{~nm}$ (reference wavelength $490 \mathrm{~nm}$ ). Measurements were performed in duplicates and mean absorbance values were calculated; the results were accepted if the precision (\% coefficient of variation) of duplicates was $\leq 20 \%$.

A floating cut point (CP) was statistically evaluated using 20 male and 20 female individual blank plasma samples according to Shankar et al. [23]. To obtain the plate-specific CP, the signal of a pooled plasma blank sample was multiplied by the plate normalization factor. Samples with signals below the plate-specific CP were considered screening negative; samples with signals at or above the plate-specific CP were considered screening positive. Due to low sample volume, a confirmation assay was not performed.

Method qualification was conducted according to the current guidelines [23,24].

\section{IC ADA assay}

The IC assay was developed as a four-step solid phase ELISA (Figure 1B). Conjugates of cynomolgus monkey or minipig IgG with human IgG spiked into blank matrix were used as QC samples. The QC concentrations were $3000 \mathrm{ng} / \mathrm{ml}$ (HQC) and $375 \mathrm{ng} / \mathrm{ml}$ (LQC) for cynomolgus [18] and $6000 \mathrm{ng} / \mathrm{ml}$ (HQC) and $175 \mathrm{ng} / \mathrm{ml}$ (LQC) for minipig assay.

Reagents and samples were incubated at room temperature with shaking at $500 \mathrm{rpm}$. Low Cross Buffer was used as assay buffer; PBS containing $0.05 \%$ Tween 20 was used as washing buffer.

Bi-labeled anti-human kappa light chain M-1.7.10 antibodies (capture antibody [20]) were bound to an SA-MTP. Samples were diluted 1:50 with assay buffer containing drug $(1 \mu \mathrm{g} / \mathrm{ml}$ for cynomolgus samples, $0.15 \mu \mathrm{g} / \mathrm{ml}$ for minipig samples), incubated for $30 \mathrm{~min}$ and then transferred onto the SA-MTP (100 $\mu$ l per well). The plate was incubated for $1 \mathrm{~h}$, washed and $100 \mu \mathrm{l}$ of Dig-labeled anti-cynomolgus monkey or anti-minipig IgG was added to each well. After $1 \mathrm{~h}$ incubation and washing, Dig was detected using the same procedure as for the bridging assay.

The CP was evaluated as described for the bridging assay. For cynomolgus, 50 (25 for each sex) and for minipig 32 (16 for each sex) individual blank plasma samples were used in duplicates.

\section{Drug quantification (human Fab fragment)}

Drug levels were determined for $\mathrm{AH}, \mathrm{VH}$ and plasma samples using a solid phase ELISA with a quantification range $0.78-50 \mathrm{ng} / \mathrm{ml}$. Reagents and samples were incubated at room temperature with shaking at $500 \mathrm{rpm}$. Low Cross Buffer was used as assay buffer; PBS containing $0.05 \%$ Tween 20 was used as washing buffer.

Briefly, a drug-specific protein was immobilized on an SA-MTP. Samples and calibration standards diluted 1:50 in the assay buffer were added and incubated for $1 \mathrm{~h}$. After washing, the bound drug was detected by adding a dioxigenylated drug-specific protein and pAb-Dig-S-Fab-HRP with ABTS used as a substrate. The color reaction was monitored at $405 \mathrm{~nm}$ (reference wavelength $490 \mathrm{~nm}$ ).

\section{Drug tolerance of minipig ADA assays}

The sample was split into 16 portions, which were spiked with an increasing amount of drug (concentration range: $0.25-500,000 \mu \mathrm{g} / \mathrm{ml}$ ). After incubation for $1 \mathrm{~h}$, the spiked samples were diluted 1:50 and immediately analyzed by the bridging assay and the minipig IC assay as described above with the variation that the IC assay was performed without additional drug spiking.

\section{Results \& discussion}

Assay qualification

Both the conventional bridging assay and the minipig IC assay demonstrated comparable qualification data with acceptable intra- and interassay precision with variation coefficients below $20 \%$. Also, both assays showed similar multiplicative normalization factors and thus comparable plate-specific CPs (Table 1). The differences in the QC concentrations reflect the differences in the assay principles and required positive control molecules. Notably, the IC assay had much lower sample consumption than the bridging assay (5 vs $12.5 \mu \mathrm{l}$ ).

\section{Drug tolerance comparison}

We investigated drug tolerance of the bridging and IC assays using a plasma sample from the minipig study, which had a high ADA signal and a residual drug level below LLOQ $(0.78 \mathrm{ng} / \mathrm{ml})$. The ADA signal in the bridging assay decreased with the increasing free drug concentration; the decrease became apparent at drug concentrations above $1 \mu \mathrm{g} / \mathrm{ml}$ and the signal fell below the CP at concentrations above $100 \mu \mathrm{g} / \mathrm{ml}$ (Figure 2). In contrast, the minipig IC 
Table 1. Qualification data for minipig immunocomplex and bridging assays.

\begin{tabular}{|c|c|c|c|c|}
\hline \multirow[t]{2}{*}{ Parameter } & \multicolumn{2}{|c|}{ Immune complex assay } & \multicolumn{2}{|c|}{ Bridging assay } \\
\hline & HQC & LQC & HQC & LQC \\
\hline QC (assay concentration) & $120 \mathrm{ng} / \mathrm{ml}$ & $3.5 \mathrm{ng} / \mathrm{ml}$ & $37.5 \mathrm{ng} / \mathrm{ml}$ & $0.75 \mathrm{ng} / \mathrm{ml}$ \\
\hline QC (matrix concentration) & $6000 \mathrm{ng} / \mathrm{ml}$ & $175 \mathrm{ng} / \mathrm{ml}$ & $750 \mathrm{ng} / \mathrm{ml}$ & $15 \mathrm{ng} / \mathrm{ml}$ \\
\hline Intra-assay precision (\% CV) & 2 & 5 & 9 & 8 \\
\hline Inter-assay precision (\%CV) & 10 & 14 & 8 & 15 \\
\hline Dilution factor & 50 ( $2 \%$ serum $)$ & & $20(5 \%$ serum $)$ & \\
\hline $\begin{array}{l}\text { Sample volume for double } \\
\text { determination }\end{array}$ & $5 \mu l$ & & $12.5 \mu \mathrm{l}$ & \\
\hline Normalization factor & 1.44 (multiplicative) & & 1.66 (multiplicative) & \\
\hline $\begin{array}{l}\text { Assay signals at screening cut } \\
\text { point (four plates) }\end{array}$ & $0.055 / 0.062 / 0.075 / 0.073$ & & $0.071 / 0.078 / 0.064 / 0.07$ & \\
\hline
\end{tabular}

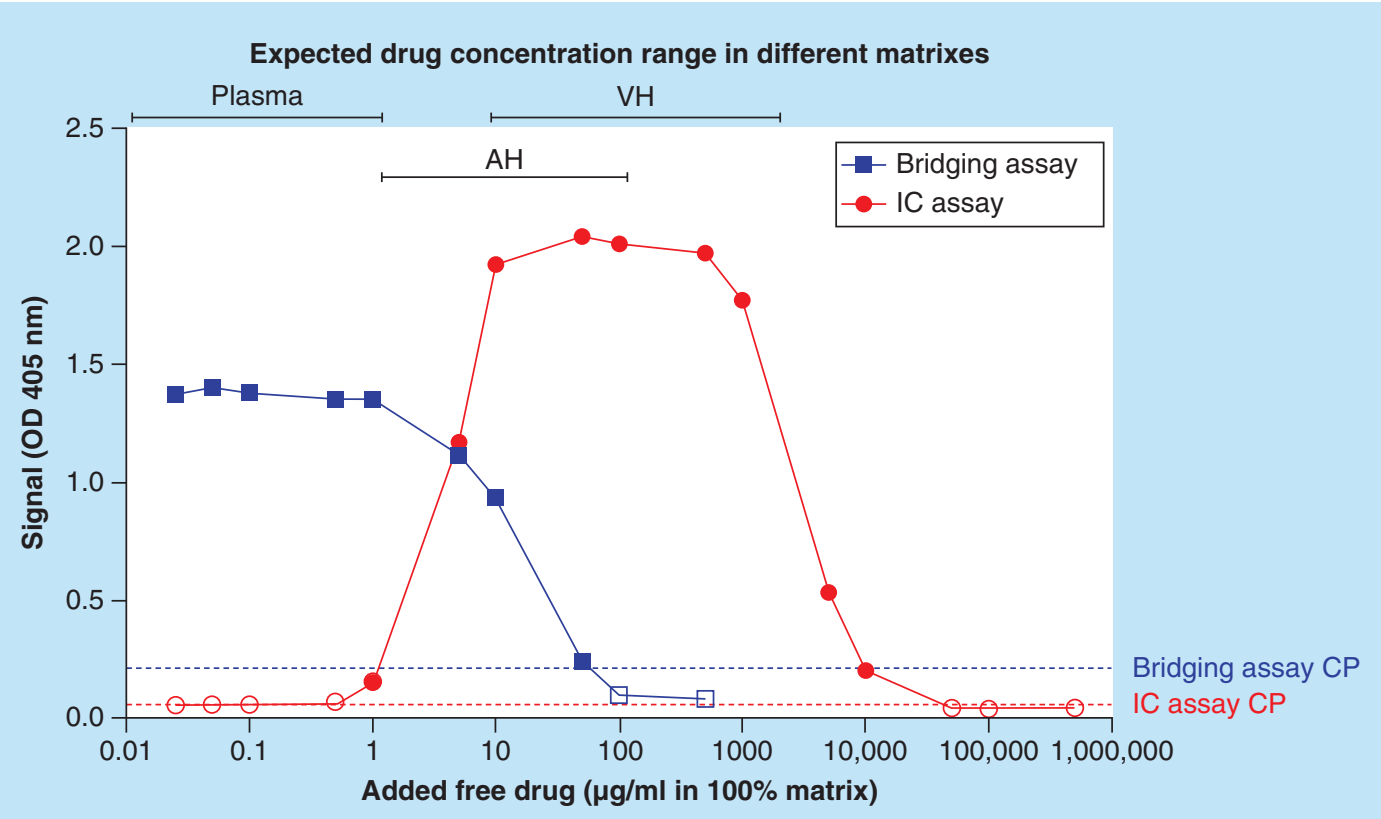

Figure 2. Influence of free drug on the bridging assay and the immune complex assay. A sample with high amount of ADA was spiked with different amount of free drug and then measured using the two ADA assays. The expected range of drug concentrations after intravitreal injections are indicated.

ADA: Antidrug antibody; AH: Aqueous humor; CP: Cut point; IC: Immune complex; VH: Vitreous humor.

assay showed a positive ADA signal in the free drug concentration range from 1 to $10,000 \mu \mathrm{g} / \mathrm{ml}$. At low free-drug concentrations, the amount of drug-ADA complexes was insufficient to generate a positive signal because the IC assay in this experiment was conducted without the spiking and pre-incubation with the drug (see Experimental section) and the residual drug concentration in the plasma sample was below LLOQ. This observation confirms that the signal generation in the IC assays requires the formation of an IC (Figure 1B). However, in routine analyses using the IC assay, low residual drug concentrations have no impact on ADA detection (see Table 2) because the standard IC assay procedure involves the addition of free drug corresponding to $7.5 \mu \mathrm{g} / \mathrm{ml}$ drug to allow for drug-ADA complex formation. The signal reduction at very high concentrations (above $1000 \mu \mathrm{g} / \mathrm{ml}$ ) was due to limited binding capacity of the SA-MTP, with the free drug displacing the drug-ADA complexes from the bound capture antibody.

Overall, the bridging assay appears to be able to correctly detect ADA at the residual drug concentrations expected for plasma and AH samples after an IVT injection, whereas it would likely lead to false-negative results at higher 
Methodology Wessels, Zadak, Reiser et al.

Table 2. ADA determination in minipig plasma samples using the immune complex and bridging assay.

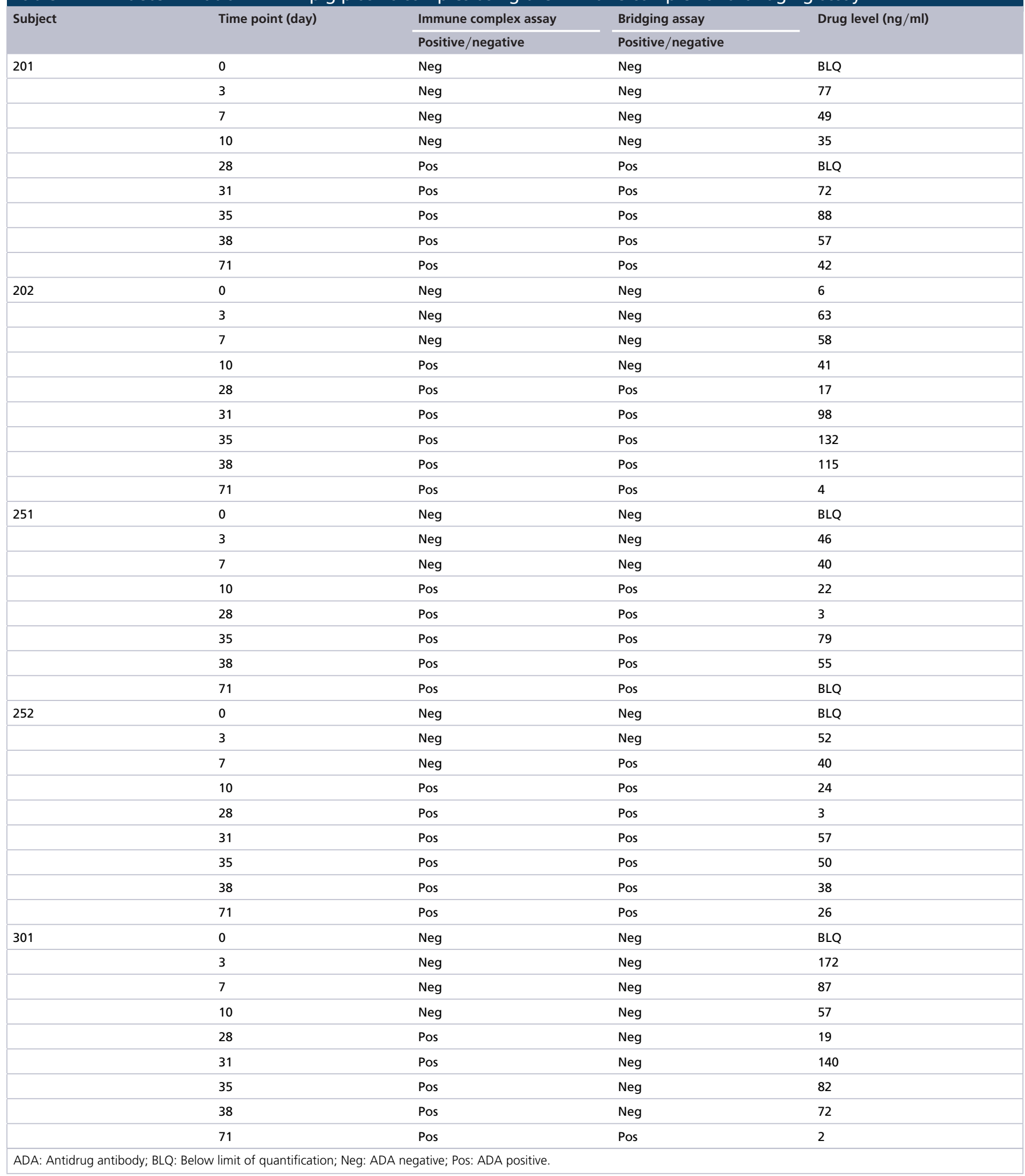


Table 2. ADA determination in minipig plasma samples using the immune complex and bridging assay (cont.).

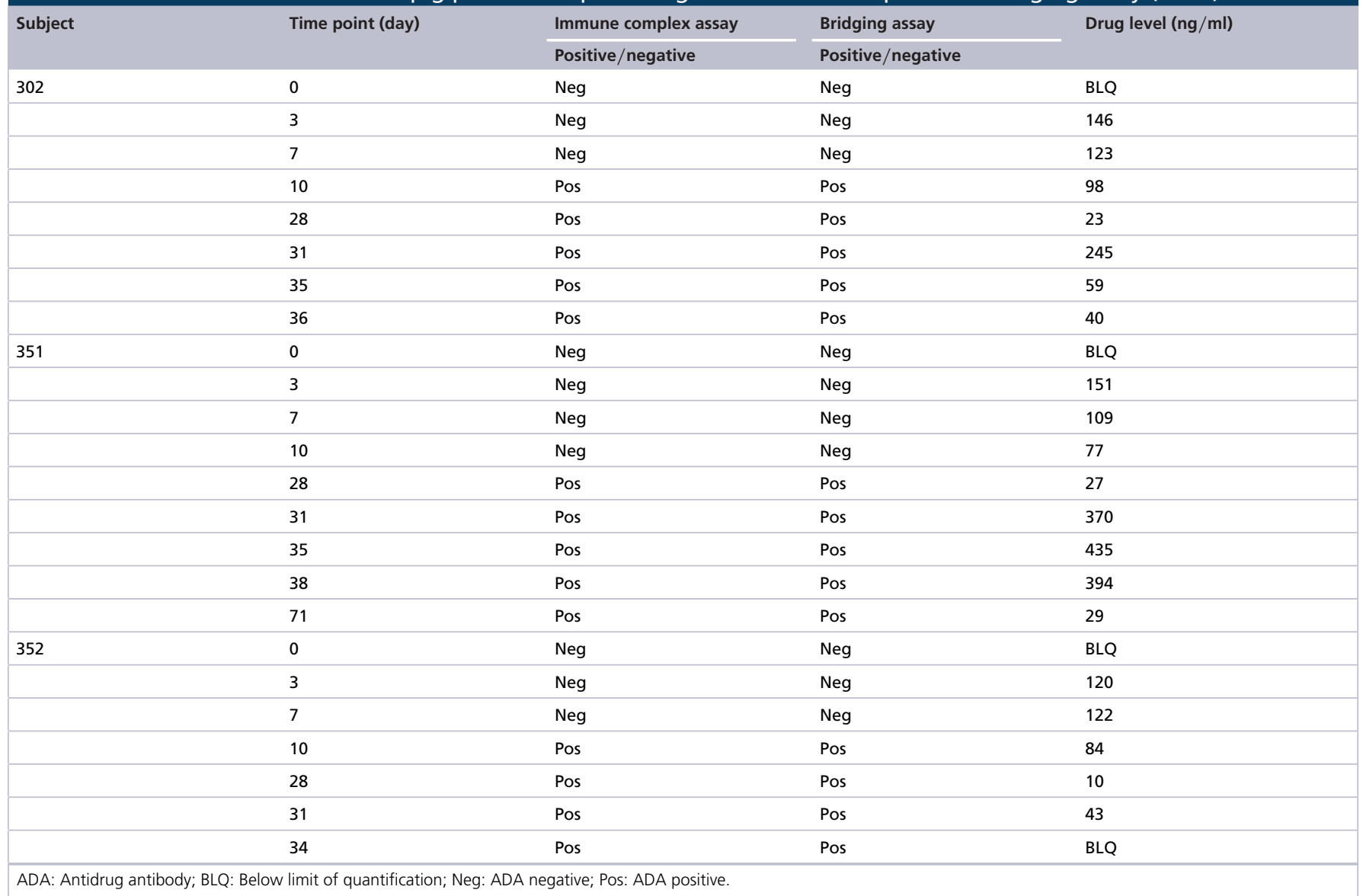

drug concentrations, which can occur in VH samples. In contrast, the IC assay demonstrated stable ADA signals over the whole range of the expected drug concentrations in ocular fluids, with only a slight signal decrease being observed at drug concentrations above $1000 \mu \mathrm{g} / \mathrm{ml}$.

Applicability of bridging \& IC assays for sample analysis in preclinical ophthalmological studies Both assays showed nearly consistent results in the ADA analysis of plasma samples from the minipig study (Table 2). The ADA assay results deviated in only six of a total of 68 plasma samples, primarily at earlier time points, with no clear correlation with the residual drug concentration. All terminal plasma samples in all animals were ADA-positive in both assays. In $\mathrm{VH}$ analyses, the bridging assay generated clearly reduced signals as compared with those of the IC assay and it failed to detect ADA in two samples that were tested positive in the IC assay and had high residual drug concentrations $(227$ and $1720 \mu \mathrm{g} / \mathrm{ml}$; Figure $3 \mathrm{~A}$ ). The IC assay results for $\mathrm{VH}$ also correlated well with those for plasma samples from the same time points (Figure 3B). Overall, the IC assay demonstrated reliable ADA detection in samples with high $(\mathrm{VH})$ and low (plasma) residual drug concentrations.

Similar results were observed in the cynomolgus study (Table 3). While ADA analysis in plasma samples was nearly consistent, the bridging assay failed to detect ADAs in the majority of AH samples on day 35 and in some $\mathrm{AH}$ and $\mathrm{VH}$ samples on day 43. The false-negative results of the bridging assay (animals 60653/60605/60606/60655/60656 at day 35 and animals 60606/60656 at day 43) correlated well with the residual drug concentration in the samples. On day 35 , the $\mathrm{AH}$ samples tested negative by the bridging assay only had higher residual drug concentrations than the two samples that were tested positive by both assays. On day 43, the lowered drug concentrations led to an increased number of positive signals in the AH samples tested by the bridging assay. Notably, the IC assay demonstrated equal results for $\mathrm{AH}$ and $\mathrm{VH}$, suggesting that the more readily accessible $\mathrm{AH}$ can be used for immunogenicity assessment in ocular fluids by means of this assay. 


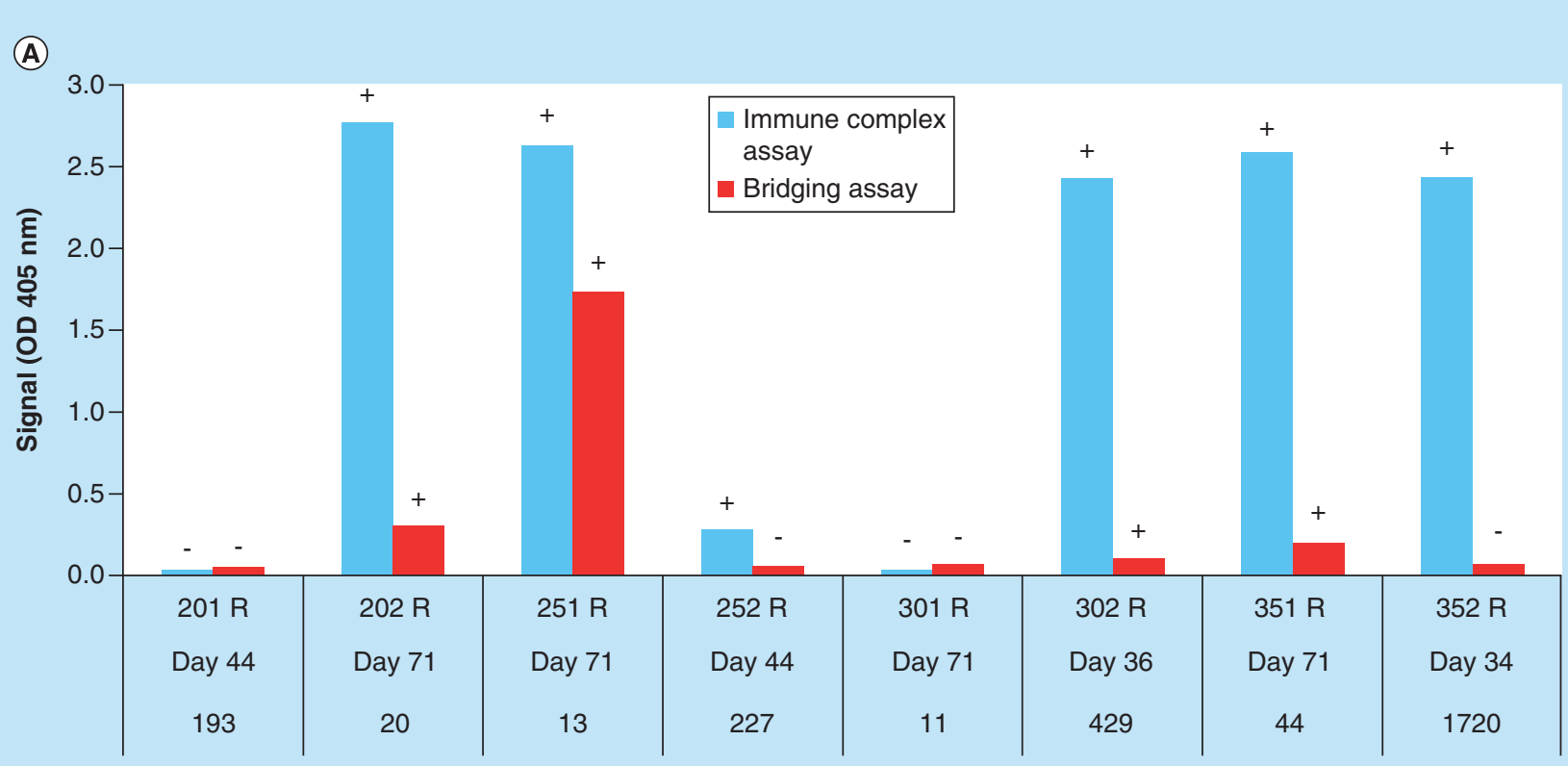

Animal time point drug $(\mu \mathrm{g} / \mathrm{ml})$

(B)

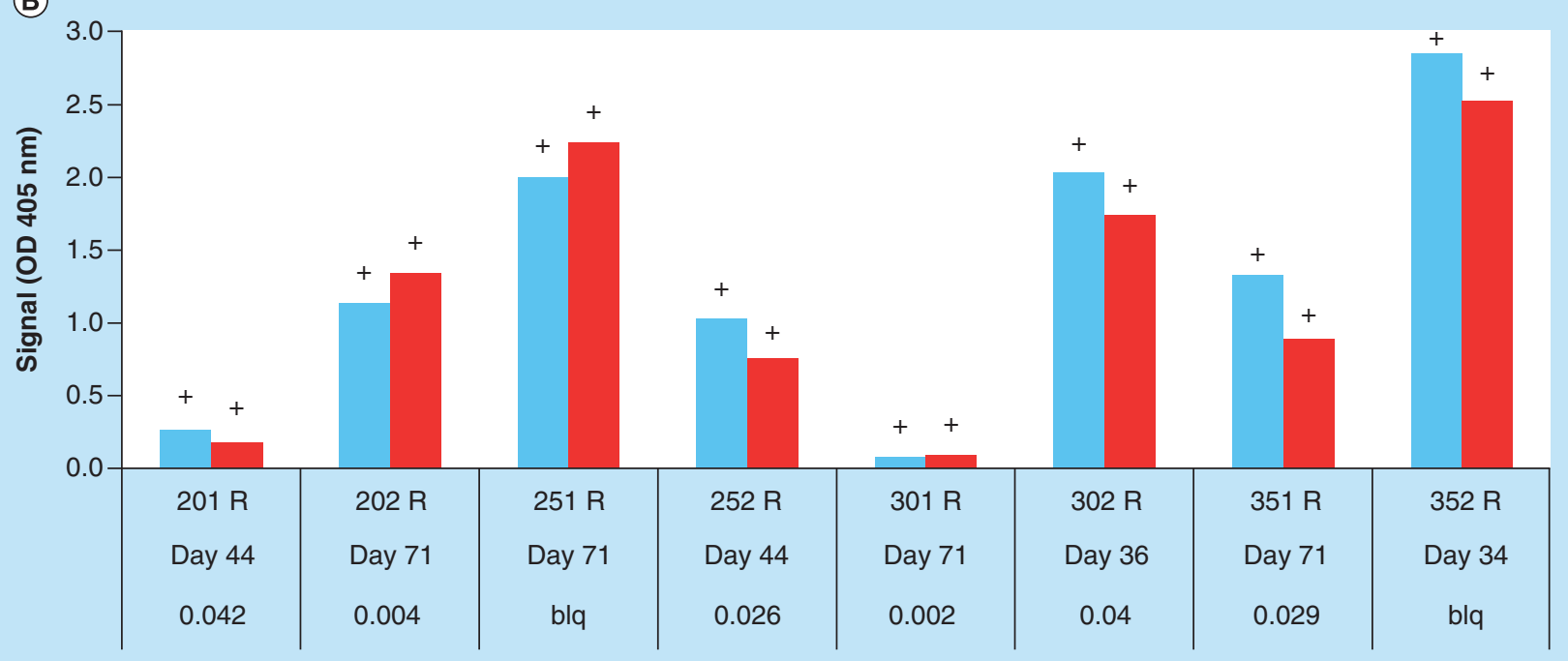

Animal time point drug $(\mu \mathrm{g} / \mathrm{ml})$

Figure 3. Minipig immunogenicity data. Antidrug antibody detection (signals) in minipig vitreous humor (A) and matched plasma samples (B). The samples were analyzed using the immune complex and bridging assay. Sampling time points and residual drug concentrations in the samples are shown on the $\mathrm{x}$-axis.

Detailed analysis of the complete dataset for cynomolgus plasma samples (data not shown) revealed positive ADA results for all eight animals in both assays. The ADA response was first detected on day 14 and it persisted until the end of the study. The majority of plasma samples (79 of a total 87) had consistent results in both assays and eight samples that showed discrepancy were all borderline positive in the IC assay and negative in the bridging assay. Two of these eight samples were taken after second dosing with higher plasma drug concentrations, the remaining six were from the animal with a weak ADA response up to day 35 (animal 60603; Table 3). Thus, the IC assay appears to be not only drug tolerant but also more sensitive, being able to detect weak ADA responses. 


\begin{tabular}{|c|c|c|c|c|c|c|c|c|c|c|}
\hline \multirow{2}{*}{$\begin{array}{l}\text { Dosing } \\
\text { group }\end{array}$} & \multirow[t]{2}{*}{ Animal } & \multicolumn{3}{|c|}{ Immune complex assay } & \multicolumn{3}{|c|}{ Bridging assay } & \multicolumn{3}{|c|}{ Drug concentration $(\mu \mathrm{g} / \mathrm{ml})$} \\
\hline & & $\mathbf{A H}$ & VH & Plasma & $\mathbf{A H}$ & VH & Plasma & $\mathbf{A H}$ & VH & Plasma \\
\hline \multirow[t]{3}{*}{$5 \mathrm{mg} /$ eye } & 60603 & Neg & NS & $\mathrm{Neg}$ & Neg & NS & $\mathrm{Neg}$ & 77 & NS & 0.2 \\
\hline & 60604 & Neg & - & Neg & Neg & - & Neg & 88 & - & 0.3 \\
\hline & 60653 & Neg & - & Neg & Neg & - & Neg & 66 & - & 0.6 \\
\hline \multirow[t]{4}{*}{$10 \mathrm{mg} /$ eye } & 60605 & Neg & - & Neg & Neg & - & Neg & 194 & - & 0.2 \\
\hline & 60606 & Neg & - & Neg & Neg & - & Neg & 262 & - & 0.4 \\
\hline & 60655 & Neg & - & Neg & Neg & - & Neg & 230 & - & 0.5 \\
\hline & 60656 & $\mathrm{Neg}$ & - & Neg & Neg & - & Neg & 217 & - & 0.8 \\
\hline \multicolumn{11}{|l|}{ Day $35 \mathrm{R}$} \\
\hline $5 \mathrm{mg} /$ eye & 60654 & Pos & - & Pos & Pos & - & Pos & 57 & - & 1.7 \\
\hline \multirow[t]{4}{*}{$10 \mathrm{mg} /$ eye } & 60605 & Pos & - & Pos & Neg & - & Pos & 211 & - & NS \\
\hline & 60606 & Pos & - & Pos & $\mathrm{Neg}$ & - & Pos & 187 & - & 0.8 \\
\hline & 60655 & Pos & - & Pos & $\mathrm{Neg}$ & - & Pos & 199 & - & NS \\
\hline & 60656 & Pos & - & Pos & $\mathrm{Neg}$ & - & Pos & 239 & - & 1.8 \\
\hline \multicolumn{11}{|l|}{ Day 43 R } \\
\hline \multirow[t]{4}{*}{$5 \mathrm{mg} /$ eye } & 60603 & Neg & $\mathrm{Neg}$ & Pos & $\mathrm{Neg}$ & Neg & Pos & 7 & 28 & 0.1 \\
\hline & 60604 & Pos & Pos & NS & Pos & Neg & NS & 213 & 624 & NS \\
\hline & 60653 & Pos & Pos & Pos & Pos & Pos & Pos & 2 & 47 & BLQ \\
\hline & 60654 & Pos & Pos & Pos & Pos & Pos & Pos & 2 & 36 & 0.2 \\
\hline
\end{tabular}

AH: Aqueous humor; BLQ: Below limit of quantification; Neg: ADA negative; NS: No sample available; Pos: ADA positive; VH: Vitreous humor.

\section{Overall discussion}

Drug tolerance comparison demonstrated the superiority of the IC assay over the bridging assay when analyzing samples with high drug concentrations. In particular, the IC assay showed a reliable ADA detection over the entire range of the expected residual drug concentrations in ophthalmological samples. The reliability and transferability of the IC assay was further confirmed in real study samples from two preclinical studies in two different species.

The results of plasma sample analysis showed only minor differences between the assays, proving that the IC assay performs comparable to the bridging ADA assay under 'normal' conditions. Because of the IVT administration of the drug, the residual drug concentration in the plasma samples was below $1 \mu \mathrm{g} / \mathrm{ml}$, in other words, below the concentration at which poor drug tolerance of the bridging assay became apparent in the drug tolerance experiment. Consequently, the bridging assay was not affected by the residual drug and showed a reliable ADA detection. In contrast, high residual drug concentration in the $\mathrm{VH}$ and $\mathrm{AH}$ samples (e.g., up to $1720 \mu \mathrm{g} / \mathrm{ml}$ in VH) prevented a reliable ADA detection using the bridging assay, while the IC assay demonstrated consistent results for ocular fluid samples with very high residual drug concentrations.

Using the IC assay, we were able to demonstrate for the first time the presence of ADA in ocular fluids such as $\mathrm{AH}$ or $\mathrm{VH}$ after IVT administration in preclinical ophthalmology studies. Moreover, the IC assay enabled us to assess the correlation of the systemic ADA response with the presence of ADA in the eye by simultaneous analysis of plasma and ocular fluid samples. In all animals, the presence of ADA in the eye was accompanied by the systemic $\mathrm{ADA}$ response, indicating that the immune response to the drug was generated systemically first and then the systemically generated ADA were transported into the eye. This finding supports the concept of the eye as an immune privileged area with several mechanisms to inhibit immune responses [8]. However, our 
current understanding of the mechanism and pathway of the immune response in the eye is far from being fully understood, as IgG antibodies were detected in $\mathrm{VH}[9]$ and the innate immune system of the eye can be activated by IVT administration of a drug [25].

A good correlation between the $\mathrm{AH}$ and $\mathrm{VH}$ samples also indicates that $\mathrm{AH}$, the preferred sampling matrix due to easy (within seconds) [26] and safe access [24], would be predictive for the ADA presence in the eye. This is in line with the previous findings demonstrating a good correlation of protein composition between $\mathrm{AH}$ and $\mathrm{VH}$, for example, for cytokine concentrations [27] and for drug elimination profiles after IVT administration of bevacizumab [28].

Overall, the systemic ADA assessment using the bridging assay performed alongside ophthalmic investigations and safety observations seems to be an appropriate strategy to assess immunogenicity after IVT administrations. If an additional analysis of the $\mathrm{ADA}$ response in $\mathrm{AH}$ or $\mathrm{VH}$ samples is required, for example, for the interpretation of pharmacokinetic data, we suggest using the IC assay to generate the most reliable data.

\section{Conclusion}

In ophthalmological studies, systemic ADA detection using the bridging assay seems to be sufficient for the immunogenicity assessment. The IC assay can, however, be used to address specific questions requiring ADA detection in ocular fluids, such as possible ADA-related toxicological findings or lack of efficacy due to aberrant pharmacokinetic profile in the eye. The good correlation of the ADA data between $\mathrm{AH}$ and $\mathrm{VH}$ can be considered for the design of future preclinical ophthalmology studies, in particular in the light of the $3 \mathrm{R}$ principle because termination of a study animal to obtain a VH sample may not be necessary. Additionally, $\mathrm{AH}$ analysis would enable a continuous monitoring of the ADA response in the eye.

Overall, the IC assay allows for a reliable ADA detection in matrices with high residual drug concentrations, such as ocular fluid samples after IVT injections, in which the bridging assay leads to false-negative results due to its poor drug tolerance. Low sample consumption $(5 \mu \mathrm{l})$ of the IC assay provides an additional benefit for the analysis. Thus, the IC assay would be particularly suitable for studies with rare and low sample volumes and high residual drug concentrations.

\section{Future perspective}

The bridging assay format will likely remain the method of choice for immunogenicity assessment in ophthalmological studies in the short term because of its widespread use, which ensures data comparability, and its ability to detect the early IgM-based response. However, regulatory authorities are encouraging sponsors to explore approaches for an improved drug-tolerance, including the use of alternative assay formats [29]. Therefore, we believe that the IC assay will be increasingly used to address specific questions, especially those requiring analysis of samples with high residual drug concentrations. The IC assay has been so far developed and used for the analysis of cynomolgus monkey, minipig and mouse samples but the assay principle allows its ease extension to other nonhuman species. However, the development of an IC ADA assay for human samples is challenging and thus will remain one of the aims of future bioanalytical research.

\section{Acknowledgements}

The authors thank R Vogel (Roche Diagnostics, Penzberg, Germany) for labeling and reagent supply and A Nürnberg (Roche, Basel, Switzerland) for the diligent preparation of the manuscript. The authors would also like to thank N Pearson and RA Sanchez for inspiring discussion and manuscript review.

\section{Financial \& competing interests disclosure}

The authors have no relevant affiliations or financial involvement with any organization or entity with a financial interest in or financial conflict with the subject matter or materials discussed in the manuscript. This includes employment, consultancies, honoraria, stock ownership or options, expert testimony, grants or patents received or pending, or royalties.

No writing assistance was utilized in the production of this manuscript.

\section{Ethical conduct of research}

The authors state that they have obtained appropriate institutional review board approval or have followed the principles outlined in the Declaration of Helsinki for all human or animal experimental investigations. In addition, for investigations involving human subjects, informed consent has been obtained from the participants involved. 


\section{Executive summary}

- The bridging and the immune complex (IC) assays demonstrated comparable qualification data. The IC assay had much lower sample consumption than the bridging assay (5 vs $12.5 \mu \mathrm{l}$ ).

- The IC antidrug antibody (ADA) assay was superior to the bridging assay in samples with high residual drug concentrations in an in vitro experiment, showing a reliable ADA detection over the entire range of the expected residual drug concentrations in ocular fluids.

- Using the minipig-specific IC assay, we were able for the first time to demonstrate a reliable ADA detection in vitreous humor (VH) after an intravitreal (IVT) injection.

- Transferability of the assay was demonstrated by the analysis of aqueous humor (AH), VH and plasma samples in a cynomolgus monkey study.

- Both assays showed similar results for the plasma sample analysis. However, the bridging assay generated inconsistent results for $\mathrm{AH}$ and $\mathrm{VH}$ samples with high residual drug concentrations.

- After IVT injection, systemic ADAs were detected in plasma earlier than in ocular fluids. Not in every case the systemic ADA response was accompanied by the presence of ADA in ocular fluids.

- The good correlation between the ADA detection in $\mathrm{AH}$ and $\mathrm{VH}$ samples justifies $\mathrm{AH}$ as a predictive matrix for the ADA detection.

- The IC assay allows for a reliable ADA detection in matrices with high residual drug concentrations, such as ocular fluid samples after IVT injections, in which the state-of-the-art bridging assay leads to false-negative results due to its poor drug tolerance. The IC assay would be particularly suitable for studies with rare and low sample volumes and high residual drug concentrations.

\section{Open access}

This work is licensed under the Attribution-NonCommercial-NoDerivatives 4.0 Unported License. To view a copy of this license, visit http://creativecommons.org/licenses/by-nc-nd/4.0/

\section{References}

1. Rodrigues EB, Farah ME, Maia M et al. Therapeutic monoclonal antibodies in ophthalmology. Prog. Retin. Eye Res. 28(2), 117-144 (2009).

2. Steinbrook R. The price of sight - ranibizumab, bevacizumab, and the treatment of macular degeneration. N. Engl. J. Med. 355(14), 1409-1412 (2006).

3. Abd AJ, Kanwar RK, Kanwar JR. Aged macular degeneration: current therapeutics for management and promising new drug candidates. Drug Discov. Today 22(11), 1671-1679 (2017).

4. Gaudreault J, Fei D, Rusit J, Suboc P, Shiu V. Preclinical pharmacokinetics of ranibizumab (rhuFabV2) after a single intravitreal administration. Invest. Ophthalmol. Vis. Sci. 46(2), 726-733 (2005).

5. de Zafra CLZ, Sasseville VG, Matsumoto $S$ et al. Inflammation and immunogenicity limit the utility of the rabbit as a nonclinical species for ocular biologic therapeutics. Regul. Toxicol. Pharmacol. 86, 221-230 (2017).

6. Ponce R, Abad L, Amaravadi L et al. Immunogenicity of biologically-derived therapeutics: assessment and interpretation of nonclinical safety studies. Regul. Toxicol. Pharmacol. 54(2), 164-182 (2009).

7. Maurice DM, Mishima S. Ocular pharmacokinetics. In: Pharmacology of the Eye. Sears ML (Ed.). Springer Berlin Heidelberg, Berlin, Germany, 19-116 (1984).

8. Stein-Streilein J. Immune regulation and the eye. Trends Immunol. 29(11), 548-554 (2008).

9. Baarsma GS, Luyendijk L, Kijlstra A et al. Analysis of local antibody production in the vitreous humor of patients with severe uveitis. Am. J. Ophthalmol. 112(2), 147-150 (1991).

10. Krohne TU, Liu Z, Holz FG, Meyer CH. Intraocular pharmacokinetics of ranibizumab following a single intravitreal injection in humans. Am. J. Ophthalmol. 154(4), 682e682-686e682 (2012).

11. Bertelmann T, Kicova N, Kohlberger L et al. Sampling aqueous humor: anterior segment anatomy, anesthetic and surgical technique, and rates of yield. Ophthalmic Res. 47(4), 214-219 (2012).

12. Inoue M, Takeda K, Morita K, Yamada M, Tanigawara Y, Oguchi Y. Vitreous concentrations of triamcinolone acetonide in human eyes after intravitreal or subtenon injection. Am. J. Ophthalmol. 138(6), 1046-1048 (2004).

13. Blana SA, Musshoff F, Hoeller T, Fimmers R, Madea B. Variations in vitreous humor chemical values as a result of pre-analytical treatment. Forensic Sci. Int. 210(1-3), 263-270 (2011).

14. Mikulskis A, Yeung D, Subramanyam M, Amaravadi L. Solution ELISA as a platform of choice for development of robust, drug tolerant immunogenicity assays in support of drug development. J. Immunol. Methods 365(1-2), 38-49 (2011). 
15. Bloem $\mathrm{K}$, van Leeuwen A, Verbeek $\mathrm{G}$ et al. Systematic comparison of drug-tolerant assays for anti-drug antibodies in a cohort of adalimumab-treated rheumatoid arthritis patients. J. Immunol. Methods 418, 29-38 (2015).

16. Zoghbi J, Xu Y, Grabert R, Theobald V, Richards S. A breakthrough novel method to resolve the drug and target interference problem in immunogenicity assays. J. Immunol. Methods 426, 62-69 (2015).

17. Sickert D, Kroeger $\mathrm{K}$, Zickler $\mathrm{C}$ et al. Improvement of drug tolerance in immunogenicity esting by acid treatment on Biacore. J. Immunol. Methods 334(1-2), 29-36 (2008).

18. Li J, Schantz A, Schwegler M, Shankar G. Detection of low-affinity anti-drug antibodies and improved drug tolerance in immunogenicity testing by Octet ${ }^{\circledR}$ biolayer interferometry. J. Pharm. Biomed. Anal. 54(2), 286-294 (2011).

19. Stubenrauch K, Wessels U, Essig U, Vogel R, Schleypen J. Evaluation of a generic immunoassay with drug tolerance to detect immune complexes in serum samples from cynomolgus monkeys after administration of human antibodies. J. Pharm. Biomed. Anal. 52(2), 249-254 (2010).

20. Stubenrauch K, Mackeben K, Vogel R, Heinrich J. Generic anti-drug antibody assay with drug tolerance in serum samples from mice exposed to human antibodies. Anal. Biochem. 430(2), 193-199 (2012).

21. Wessels U, Schick E, Ritter M, Kowalewsky F, Heinrich J, Stubenrauch K. Novel drug and soluble target tolerant antidrug antibody assay for therapeutic antibodies bearing the P329G mutation. Bioanalysis 9(11), 849-859 (2017).

22. Zhong ZD, Clements-Egan A, Gorovits B et al. Drug target interference in immunogenicity assays: recommendations and mitigation strategies. AAPS J. 19(6), 1564-1575 (2017).

23. Shankar G, Devanarayan V, Amaravadi L et al. Recommendations for the validation of immunoassays used for detection of host antibodies against biotechnology products. J. Pharm. Biomed. Anal. 48(5), 1267-1281 (2008).

24. Koren E, Smith HW, Shores E et al. Recommendations on risk-based strategies for detection and characterization of antibodies against biotechnology products. J. Immunol. Methods 333(1-2), 1-9 (2008).

25. Wakshull E, Quarmby V, Mahler HC et al. Advancements in understanding immunogenicity of biotherapeutics in the intraocular space. AAPS J. 19(6), 1656-1668 (2017).

26. O’Rourke J, Taylor DM, Wang Y. Compact bulb pipette simplifies paracentesis. Ophthalmic Surg. Lasers Imaging 35(2), 172-173 (2004).

27. Funatsu H, Yamashita H, Noma $\mathrm{H}$ et al. Aqueous humor levels of cytokines are related to vitreous levels and progression of diabetic retinopathy in diabetic patients. Graefes Arch. Clin. Exp. Ophthalmol. 243(1), 3-8 (2005).

28. Bakri SJ, Snyder MR, Reid JM, Pulido JS, Singh RJ. Pharmacokinetics of intravitreal bevacizumab (Avastin). Ophthalmology 114(5), 855-859 (2007).

29. Gupta S, Richards S et al. 2017 White Paper on recent issues in bioanalysis: a global perspective on immunogenicity guidelines $\&$ biomarker assay performance (part 3 - LBA: immunogenicity, biomarkers and PK assays). Bioanalysis 9(24), 1967-1996 (2017). 